\title{
Teaching Video NeuroImages: Slow periodic myoclonus in subacute sclerosing panencephalitis and fulminant Wilson disease
} Roger M. Meza, MD, Hans Schulz, MD, Juan Correa, MD, Mayra Rojas, MD, Vivek Lal, MD, and
Alberto J. Espay, MD, MSc

Neurology ${ }^{\circledR}$ 2019;93:e1410-e1411. doi:10.1212/WNL.0000000000008206
Correspondence

Dr. Espay

alberto.espay@uc.edu

Figure Neuroimaging in case 2 (fulminant Wilson disease)

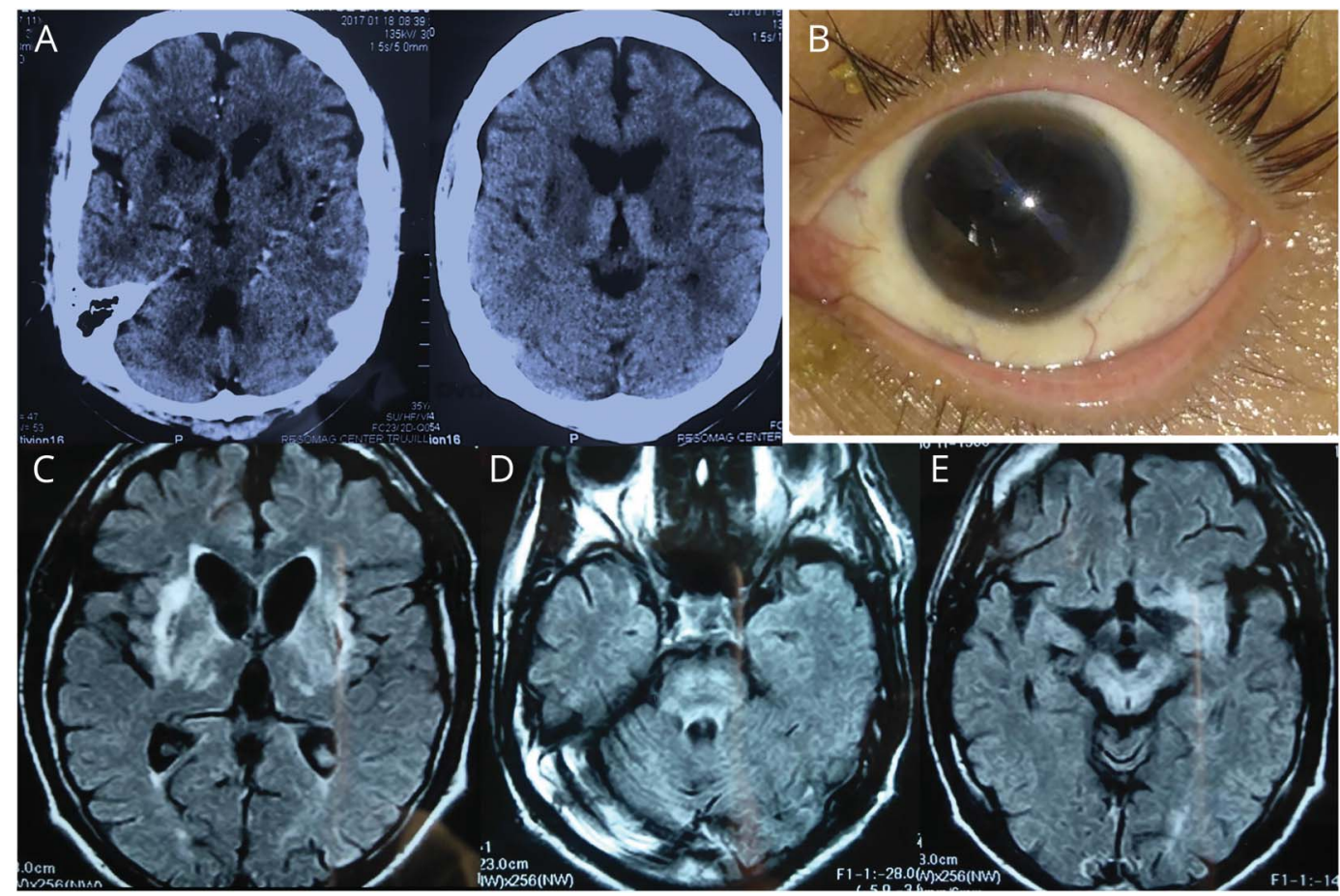

(A) Head CT shows hypodense putamen and hyperdense medial thalami. (B) Eyes with Kayser-Fleischer rings. Brown rings encircle the iris, due to corneal copper deposition. (C-E) Axial fluid-attenuated inversion recovery brain MRI demonstrates heterogeneous hyperintense signal in the ganglia (C), pons (D, "face of the panda cub"), and midbrain (E, "face of the giant panda").

Slow periodic myoclonus is a well-recognized phenotype of fulminant subacute sclerosing panencephalitis (video 1). ${ }^{1}$ This distinctive phenotype has not been previously recognized in another rapidly progressive disorder, fulminant Wilson disease. We documented slow periodic myoclonus in a 34-year-old Peruvian man who developed paranoid schizophrenia and, 6 months later, levodopa-unresponsive parkinsonism and falls, progressing into akinetic mutism (video 2). Prior to death, the diagnosis of Wilson disease was supported by ocular and neuroimaging features (figure), low ceruloplasmin $(5.3 \mathrm{U} / \mathrm{L})$, high urinary copper, and diffuse hepatopathy on echography. Slow periodic flexor myoclonus reflects cortical excitability and bears a poor prognosis. ${ }^{2}$ The EEG correlates are generalized, high-amplitude, quasiperiodic complexes.

\section{MORE ONLINE}

$\rightarrow$ Teaching slides

links.lww.com/WNL/

A965

○ Videos 


\section{Author contributions}

R.M. Meza drafted the manuscript and created the videotape. H. Schulz, J. Correa, and M. Rojas evaluated the patient with Wilson disease and participated in the review of the manuscript. V. Lal evaluated the patient with subacute sclerosing panencephalitis and participated in the review of the manuscript. A.J. Espay provided critical review of the cases and participated in the review of the manuscript.

\section{Study funding}

No targeted funding reported.

\section{Disclosure}

R.M. Meza, H. Schulz, J. Correa, M. Rojas, and V. Lal report no disclosures. A.J. Espay has received grant support from the
NIH, Great Lakes Neurotechnologies, and the Michael J Fox Foundation; personal compensation as a consultant/scientific advisory board member for AbbVie, TEVA, Impax, Acadia, Acorda, Cynapsus/Sunovion, Lundbeck, and USWorldMeds; publishing royalties from Lippincott Williams \& Wilkins, Cambridge University Press, and Springer; and honoraria from AbbVie, UCB, USWorldMeds, Lundbeck, Acadia, the American Academy of Neurology, and the Movement Disorders Society. Go to Neurology.org/N for full disclosures.

\section{References}

1. Gagnon A, Bouchard RW. Fulminating adult-onset subacute sclerosing panencephalitis in a 49-year-old man. Arch Neurol 2003;60:1160-1161.

2. Oga T, Ikeda A, Nagamine $T$, et al. Implication of sensorimotor integration in the generation of periodic dystonic myoclonus in subacute sclerosing panencephalitis (SSPE). Mov Disord 2000;15:1173-1183. 


\section{Neurology}

Teaching Video NeuroImages: Slow periodic myoclonus in subacute sclerosing panencephalitis and fulminant Wilson disease

Roger M. Meza, Hans Schulz, Juan Correa, et al.

Neurology 2019;93; e1410-e1411

DOI 10.1212/WNL.0000000000008206

This information is current as of September 30, 2019

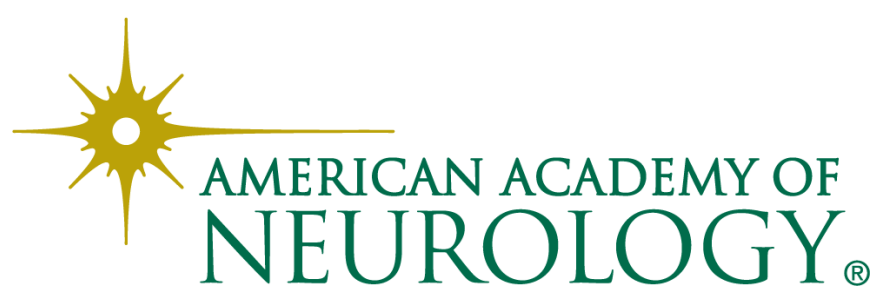




\section{Updated Information \& Services}

References

Citations

Subspecialty Collections

Errata

Permissions \& Licensing

\section{Reprints}

including high resolution figures, can be found at: http://n.neurology.org/content/93/14/e1410.full

This article cites 2 articles, 0 of which you can access for free at: http://n.neurology.org/content/93/14/e1410.full\#ref-list-1

This article has been cited by 2 HighWire-hosted articles: http://n.neurology.org/content/93/14/e1410.full\#\#otherarticles

This article, along with others on similar topics, appears in the following collection(s):

All Clinical Neurology

http://n.neurology.org/cgi/collection/all_clinical_neurology All Cognitive Disorders/Dementia http://n.neurology.org/cgi/collection/all_cognitive_disorders_dementia All Medical/Systemic disease http://n.neurology.org/cgi/collection/all_medical_systemic_disease Metabolic disease (inherited)

http://n.neurology.org/cgi/collection/metabolic_disease_inherited Myoclonus

http://n.neurology.org/cgi/collection/myoclonus

An erratum has been published regarding this article. Please see next page or:

/content/94/16/724.2.full.pdf

Information about reproducing this article in parts (figures,tables) or in its entirety can be found online at:

http://www.neurology.org/about/about_the_journal\#permissions

Information about ordering reprints can be found online:

http://n.neurology.org/subscribers/advertise

Neurology ${ }^{\circledR}$ is the official journal of the American Academy of Neurology. Published continuously since 1951, it is now a weekly with 48 issues per year. Copyright @ 2019 American Academy of Neurology. All rights reserved. Print ISSN: 0028-3878. Online ISSN: 1526-632X.

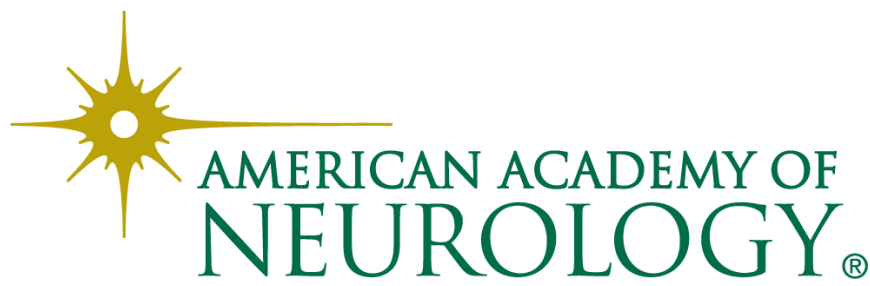




\section{Disputes \& Debates: Editors' Choice}

Steven Galetta, MD, FAAN, Section Editor

\section{Editors' note: Insular and anterior cingulate cortex deep stimulation for central neuropathic pain: Disassembling the percept of pain}

In the article "Insular and anterior cingulate cortex deep stimulation for central neuropathic pain: Disassembling the percept of pain," Dr. Galhardoni et al. compared the analgesic effects of repetitive transcranial magnetic stimulation (rTMS) of the anterior cingulate cortex (ACC) or the posterior superior insula (PSI) against sham deep rTMS in 98 patients with central neuropathic pain (CNP) after stroke or spinal cord injury in a randomized, double-blinded, sham-controlled, 3-arm parallel study. They found that ACC- and PSIrTMS were not different from sham-rTMS for pain relief despite a significant increase in heat thresholds after insular stimulation and anxiolytic effects after ACC-rTMS and concluded that different dimensions of pain can be modulated noninvasively by directly stimulating deeper structures without necessarily improving clinical pain. In response, Dr. Zugaib et al. point to their recent work suggesting that PSI-/ACC-rTMS involves more intense stimulation of superficial structures. They argue that the use of linear projection to estimate the stimulation targets—as was the case in the trial—does not correspond to the region of maximum-induced electrical field, which is more superficial, and therefore caution against interpreting the clinical findings as resulting from the stimulation of deep structures as opposed to a combination of stronger superficial and deeper stimulation. They suggest using electric field modeling to guide the coil positioning and adjustment of stimulation intensity. Responding to these comments, Dr. de Andrade et al. defend the precision of their approach, noting that in addition to linear projection-guided PSI stimulation providing antinociceptive effects in patients with CNP and healthy volunteers, direct cortical stimulation of the PSI during stereo-EEG in a previous study showed the same heat-pain changes as described by linear projection-target deep TMS. They also note that stimulation intensity was calculated using the tibialis anterior muscle as a parameter, represented medially in the primary motor cortex, suggesting that a measurable current was likely delivered to the PSI. They argue that computing electric fields would not solve the issue of stimulation intensity, and instead propose that future field models should account for the data from linear projection, validated against sham and active controls, in their algorithms. This exchange highlights the important points of debate in the field of rTMS regarding the most reliable means of targeting deeper structures in the brain, and conversely, identifying the responsible structural mediators of observed stimulation effects.

\section{Reader response: Insular and anterior cingulate cortex deep stimulation for central neuropathic pain: Disassembling the percept of pain}

João Zugaib (Ilhéus, Brazil), Janine R. Camatti (Santo André, Brazil), and Victor Hugo Souza (Espoo, Finland) Neurology ${ }^{\circledR}$ 2020;94:720-721. doi:10.1212/WNL.0000000000009303

Galhardoni et al. ${ }^{1}$ evaluated the effect of repetitive transcranial magnetic stimulation (rTMS) on the anterior cingulate cortex (ACC) and posterior superior insula (PSI) of patients with central 
neuropathic pain (CNP). Multidimensional aspects of pain were evaluated with psychophysical tests, electrophysiologic recordings, and scales. rTMS in PSI increased the threshold for heat pain, whereas in ACC improved anxiety scores. It is plausible that the neuromodulation of these structures has a therapeutic potential for $\mathrm{CNP}^{2}$ On the other hand, we recently pointed out that rTMS over PSI and ACC involve greater stimulation of superficial rather than deeper structures. ${ }^{3}$ In addition, estimation of the stimulation targets was based on a linear projection from the center of the coil. ${ }^{4}$ Linear projection does not correspond to the region of maximum induced electric field on internally folded cortical structures, which is always on the more superficial tissue ${ }^{5}$; therefore, the clinical findings should not be regarded as the resultant of deep structures' stimulation instead of an ensemble of stronger spread superficial stimulation combined with deeper stimulation. Accordingly, electric field modeling may be used to guide the coil positioning and adjustment of stimulation intensity to achieve a significant pain relief. Certainly, there is great importance in the development of new therapeutic strategies for CNP.

1. Galhardoni R, Aparecida da Silva V, García-Larrea L, et al. Insular and anterior cingulate cortex deep stimulation for central neuropathic pain: Disassembling the percept of pain. Neurology 2019;92:e2165-e2175.

2. Peyron R, Fauchon C. The posterior insular-opercular cortex: an access to the brain networks of thermosensory and nociceptive processes? Neurosci Lett 2019;702:34-39.

3. Zugaib J, Souza VH. Transcranial magnetic stimulation for neuromodulation of the operculo-insular cortex in humans. J Physiol 2019; 597:677-678.

4. Hagiwara K, Isnard J, Peyron R, Garcia-Larrea L. Theta-burst-induced seizures reported by Lenoir et al: anterior or posterior insular seizures? Brain Stimul 2019;12:200-201.

5. Deng ZD, Lisanby SH, Peterchev AV. Electric field depth-focality tradeoff in transcranial magnetic stimulation: simulation comparison of 50 coil designs. Brain Stimul 2013;6:1-13.

Copyright (c) 2020 American Academy of Neurology

\section{Author response: Insular and anterior cingulate cortex deep stimulation for central neuropathic pain: Disassembling the percept of pain}

Daniel Ciampi de Andrade (São Paulo, Brazil), Ricardo Galhardoni (São Paulo, Brazil),

Valquíria Aparecida da Silva (São Paulo, Brazil), Luís García-Larrea (Lyon, France), Camila Dale (São Paulo,

Brazil), Abrahão F. Baptista (Santo André, Brazil), Luciana Mendonça Barbosa (São Paulo, Brazil),

Luciana Mendes Bahia Menezes (São Paulo, Brazil), Silvia R.D.T. de Siqueira (São Paulo, Brazil),

Fernanda Valério (São Paulo, Brazil), Jefferson Rosi (São Paulo, Brazil), Antonia Lilian de Lima Rodrigues (São

Paulo, Brazil), Diego Toledo Reis Mendes Fernandes (São Paulo, Brazil), Priscila Mara Lorencini Selingardi (São

Paulo, Brazil), Marco Antônio Marcolin (São Paulo, Brazil), Fábio Luís de Souza Duran (São Paulo, Brazil),

Carla Rachel Ono (São Paulo, Brazil), Leandro Tavares Lucato (São Paulo, Brazil), Ana Mércia B. L. Fernandes (São Paulo, Brazil), Fábio E. F. da Silva (São Paulo, Brazil), Lin T. Yeng (São Paulo, Brazil), André R. Brunoni (São Paulo, Brazil), Carlos A. Buchpiguel (São Paulo, Brazil), and Manoel J. Teixeira (São Paulo, Brazil) Neurology ${ }^{\circledR}$ 2020;94:721-722. doi:10.1212/WNL.0000000000009304

We thank Dr. Zugaib et al. for the interest in our work. ${ }^{1}$ It has been suggested that modeling electric fields within the deep cortical structures would provide more reliable, target-effect conclusions. So far, the use of linear projection to target ${ }^{1}$ the posterior superior insula (PSI) has provided antinociceptive effects as measured by increases in the heat-pain threshold in patients with central pain ${ }^{2}$ and in healthy volunteers. ${ }^{30}$ Importantly, in a unique study, ${ }^{4}$ direct cortical stimulation of the PSI during stereo-EEG showed exactly ${ }^{4}$ the same heat-pain changes described by the linear projection-targeted deep transcranial magnetic stimulation (TMS). Taken together, these are very strong arguments for the precision of such an approach. In addition, in the setups cited above, stimulation intensity was calculated using the anterior tibialis muscle as a parameter (with the leg representation buried medially within the primary motor cortex), which attests that a measurable amount of induced electric current was indeed delivered to the PSI. As pointed out by Zugaib and Souza, ${ }^{5}$ computing electric field would not solve the issue of intensity of stimulation. Because the linear projection-based deep TMS approach proved itself accurate on 
psychophysical terms, we propose a pragmatic "reverse-modeling" perspective that future electricfield models should take into account the data from linear projection in their algorithms because they have been validated against sham and active controls and provided information on the intensity of stimulation all at once.

1. Ciampi de Andrade D, Galhardoni R, Pinto LF, et al. Into the island: a new technique of non-invasive cortical stimulation of the insula. Neurophysiol Clin 2012;42:363-368.

2. Galhardoni R, Aparecida da Silva V, García-Larrea L, et al. Insular and anterior cingulate cortex deep stimulation for central neuropathic pain: Disassembling the percept of pain. Neurology 2019;92:e2165-e2175.

3. Lenoir C, Algoet M, Mouraux A. Deep continuous theta burst stimulation of the operculo-insular cortex selectively affects A $\delta$-fibre heat pain. J Physiol 2018;596:4767-4787.

4. Denis DJ, Marouf R, Rainville P, Bouthillier A, Nguyen DK. Effects of insular stimulation on thermal nociception. Eur J Pain 2016;20: $800-810$.

5. Zugaib J, Souza VH. Transcranial magnetic stimulation for neuromodulation of the operculo-insular cortex in humans. J Physiol 2019; 597:677-678.

Copyright @ 2020 American Academy of Neurology

\section{Editors' note: Clinical manifestations of homozygote allele carriers in Huntington disease}

In the article "Clinical manifestations of homozygote allele carriers in Huntington disease", Dr. Cubo et al. examined the phenotypic differences between patients who were homozygous for Huntington disease (HD) — with both alleles carrying $\geq 36$ CAG repeats—and those who were heterozygous with only one allele carrying such repeats, in 10,921 participants with HD in an international, longitudinal, case-control study (European Huntington's Disease Network Registry database). They found that homozygotes were infrequent $(0.3 \%)$ and that the age at onset, HD phenotype, and disease progression did not differ significantly between homozygotes and heterozygotes. In response, Dr. Da Prat et al. noted a previous study that reported a more severe and rapid progression in homozygotes. They suggest using the term biallelic $\mathrm{HD}$ to refer to these patients to acknowledge the differences in the number of repeats that may exist between the 2 expanded alleles and cite a previous abstract from their group that also reported no differences in age at onset, cognition, motor capabilities, or disease evolution between a small sample of 7 patients with biallelic HD and heterozygous patients. Responding to these comments, Drs. Ramos-Arroyo and Cubo highlighted the potential drawbacks of using the term biallelic $\mathrm{HD}$, noting the differences between patients with 2 expanded alleles carrying $\geq 36$ CAG repeats vs those with one intermediate allele (27-35 repeats) who may have lateronset disease (both groups are combined under the biallelic definition), and noting the exclusion of compound heterozygotes with 2 nonfully penetrant repeat expansions from the conventional biallelic definition. They argue that these issues lead to imprecise categorization of patients with $\mathrm{HD}$ and potential noise in the analysis of clinical effects. This exchange illustrates the potential challenges that can arise in the interpretation of genotypic-phenotypic correlation studies from the use of what may appear at the first glance to be superficially discrepant definitions.

Aravind Ganesh, MD, DPhil, and Steven Galetta, MD

Neurology ${ }^{\circledR}$ 2020;94:722. doi:10.1212/WNL.0000000000009305 


\section{Reader response: Clinical manifestations of homozygote allele carriers in Huntington disease}

Gustavo Da Prat (Buenos Aires), Jose Luis Etcheverry (Buenos Aires), Martin Cesarini (Buenos Aires), and Emilia Gatto (Buenos Aires)

Neurology ${ }^{\circledR}$ 2020;94:723. doi:10.1212/WNL.0000000000009307

We read with interest the article by Cubo et al. ${ }^{1}$ Patients with homozygous Huntington disease (HD) are rare-considering a patient as homozygous when presenting with repetitions greater than 36 in both alleles. Differences in age at onset, clinical characteristics, and evolution have been hypothesized because the gain function of the mutation is due to both alleles. Nevertheless, it has been shown that these patients have a similar clinical evolution. However, a very early study conducted by Squitieri et al. $^{2}$ reported a more severe and rapid progression in homozygotes.

The term biallelic HD (B-HD) was introduced to describe those individuals with 1 mutated allele ( $\geq 40$ CAG repeats) and one with $\geq 27$ CAG repeats to differentiate them from individuals with 2 identical CAG repeats (true homozygous) or 1 fully expanded heterozygous ( $\geq 40$ CAG repeats) allele. For this reason, we suggest the categorization of B-HD instead of "homozygous," as a more appropriate nomenclature. ${ }^{3}$

In our database, we identified 7 patients with B-HD among 150 patients with $\mathrm{HD}$ from June 2003 to May 2019. Coinciding with Cubo et al., ${ }^{1}$ we found no differences regarding the age at onset, cognition, motor capabilities, or disease evolution in patients with B-HD compared with the heterozygous patients with $\mathrm{HD}{ }^{4}$

1. Cubo E, Martinez-Horta SI, Santalo FS, et al. Clinical manifestations of homozygote allele carriers in Huntington disease. Neurology 2019;92:e2101-e2108.

2. Squitieri F, Gellera C, Cannella M, et al. Homozygosity for CAG mutation in Huntington disease is associated with a more severe clinical course. Brain 2003;126:946-955.

3. Uhlmann WR, Peñaherrera MS, Robinson WP, Milunsky JM, Nicholson JM, Albin RL. Biallelic mutations in huntington disease: a new case with just one affected parent, review of the literature and terminology. Am J Med Genet A 2015;167A:1152-1160.

4. Cesarini M, Parisi V, Persi G, et al. A retrospective analysis of clinical forms and age of onset of biallelic Huntington disease patients from an Argentinean Center [abstract]. Mov Disord 2017;32. Available at: mdsabstracts.org/abstract/a-retrospective-analysis-of-clinicalforms-and-age-of-onset-of-biallelic-huntington-disease-patients-from-an-argentinean-center/. Accessed May 3, 2019.

Copyright (c) 2020 American Academy of Neurology

\section{Author response: Clinical manifestations of homozygote allele carriers in Huntington disease}

Maria A. Ramos-Arroyo (Pamplona, Spain) and Esther Cubo (Burgos, Spain)

Neurology ${ }^{\circledR}$ 2020;94:723-724. doi:10.1212/WNL.0000000000009308

We appreciate the comments of Da Prat et al. comparing the results of our study ${ }^{1}$ with their conclusions on the assessment of additional cases with 2 expanded HTT gene copies. ${ }^{2}$

Regarding terminology, we agree that "biallelic HD/mutations/expansions" might be an alternative term for the carriers of 2 expanded HTT alleles. By definition, biallelic carriers have a mutation in both maternal and paternal gene copies. For Huntington disease (HD), it could, therefore, include homozygotes for a particular CAG expansion and compound heterozygotes, carrying 2 different pathogenic alleles.

However, the term biallelic HD, as defined by Da Prat et al., presents, in our opinion, some major drawbacks. First, it is not useful in the analysis of genotype/phenotype relationships of the carriers 
with 1 and 2 expanded ( $\leq 36$ CAGs) HTT copies (homozygotes and compound heterozygotes), as in our study. ${ }^{1}$ Second, sequences of 27-35 CAG repeats are considered mutated/expanded alleles. We and others have observed that intermediate alleles (IAs) might confer late-onset abnormal motor and/or cognitive phenotype. ${ }^{3}$ However, at present, IAs are considered unstable but are seen as non-HD-causing alleles. ${ }^{4}$ Thus, their inclusion in the mutation range of the HTT gene seems premature and confusing. Third, the term excludes the compound heterozygotes in patients with $\mathrm{HD}$ carrying 2 nonfully penetrant CAG repeats.

In conclusion, we think that the term biallelic mutations leads to imprecision in grouping and categorization of patients with $\mathrm{HD}$, adding "noise" to the analysis of their clinical effects. In fact, it has not been previously used in other diseases caused by repeat expansion mutations.

1. Cubo E, Martinez-Horta SI, Santalo FS, et al. Clinical manifestations of homozygote allele carriers in Huntington disease. Neurology 2019;92:e2101-e2108.

2. Cesarini M, Parisi V, Persi G, et al. A retrospective analysis of clinical forms and age of onset of biallelic Huntington disease patients from an Argentinean Center. Mov Disord 2017;32(suppl 2). Abstract.

3. Cubo E, Ramos-Arroyo MA, Martinez-Horta S, et al. Clinical manifestations of intermediate allele carriers in Huntington disease. Neurology 2016;87:571-578.

4. Caron NS, Wright GEB, Hayden MR. Huntington disease. In: Adam MP, Ardinger HH, Pagon RA, et al, editors. GeneReview ${ }^{\circ}$ [Internet]. Seattle: University of Washington; 1998:1993-2019. Updated 2018 Jul 5.

Copyright @ 2020 American Academy of Neurology

CORRECTIONS

\section{Myasthenic crisis demanding mechanical ventilation: A multicenter analysis of 250 cases}

Neurology ${ }^{\circledR} 2020 ; 94: 724$. doi:10.1212/WNL.0000000000009262

In the Clinical/Scientific Note "Myasthenic crisis demanding mechanical ventilation: A multicenter analysis of 250 cases" by Neumann et al., ${ }^{1}$ Dr. Schneider's first name should be listed as Hauke. The authors regret the error.

\section{Reference}

1. Neumann B, Angstwurm K, Mergenthaler P, et al. Myasthenic crisis demanding mechanical ventilation: a multicenter analysis of 250 cases. Neurology 2020;94:e299-e313.

\section{Teaching Video NeuroImages: Slow periodic myoclonus in subacute sclerosing panencephalitis and fulminant Wilson disease}

Neurology ${ }^{\circledR} 2020 ; 94: 724$. doi:10.1212/WNL.0000000000009393

In the article "Teaching Video NeuroImages: Slow periodic myoclonus in subacute sclerosing panencephalitis and fulminant Wilson disease" by Meza et al., ${ }^{1}$ the videos should be swapped so that the first video corresponds with the second legend and vice versa. The authors regret the errors.

\section{Reference}

1. Meza RM, Schulz H, Correa J, et al. Teaching Video NeuroImages: Slow periodic myoclonus in subacute sclerosing panencephalitis and fulminant Wilson disease. Neurology 2019;93:e1410-e1411. 